\title{
A Life Cycle Model of Health and Retirement: The Case of Swedish Pension Reform*
}

\author{
Tobias Laun ${ }^{\dagger} \quad$ Johanna Wallenius ${ }^{\ddagger}$
}

March 12, 2012

SSE/EFI Working Paper Series in Economics and Finance

No. 741

\begin{abstract}
In this paper we develop a life cycle model of labor supply and retirement to study the interactions between health and the labor supply behavior of older workers, in particular disability insurance and pension claiming. In our framework, individuals choose when to stop working and, given eligibility criteria, when/if to apply for disability and pension benefits. Individuals care about their health and can partially insure against health shocks by investing in health. We use the model to study the labor supply implications of the recent Swedish pension reform. We find that the new pension system creates big incentives for the continued employment of older workers. In particular, the model predicts an increase in the average retirement age of more than two years.
\end{abstract}

JEL classification: E24, J22, J26

Keywords: Life cycle, retirement, pension reform, disability insurance, health

${ }^{*}$ We thank Lars Ljungqvist and David Domeij for their valuable suggestions. We also thank seminar participants at Uppsala University for their comments. Laun gratefully acknowledges financial support from the Jan Wallander and Tom Hedelius Foundation at Svenska Handelsbanken.

${ }^{\dagger}$ Department of Economics, Stockholm School of Economics

\#Department of Economics, Stockholm School of Economics 


\section{Introduction}

Faced with ageing populations and the looming insolvency of social security, governments the world over are grappling with the question of how to reform retirement programs. Understanding how changes to retirement programs affect life cycle labor supply, particularly retirement behavior, is critical for assessing the effects of these changes on allocations, welfare and government finances. Accurate assessments require a model of retirement that captures the key forces underlying retirement decisions.

Various institutional features have potentially large implications for the labor supply behavior of older workers; key among them are the design of pension systems, disability insurance and healthcare. Disability insurance is particularly relevant, as in many countries a large fraction of retirement occurs before the normal retirement age. A discussion of disability insurance programs naturally leads to a discussion of health, as disability insurance programs without exception have some eligibility criteria regarding health. Health, in turn, has potential implications for labor supply outcomes both directly and through the healthcare system.

In this paper, we construct a life cycle model of labor supply and retirement, which enables us to study the interactions between health, disability insurance and old-age retirement benefits. The key features of our framework are that individuals choose when to stop working and, given eligibility criteria, when/if to apply for disability and pension benefits. Individuals care about their health and can partially insure against health shocks by investing in health. The fact that people can impact their own health and choose whether or not to claim disability benefits, are novel features in relation to the existing literature.

While many countries have come to understand the need for social security reform, Sweden is one of the few countries to have actually undertaken a major pension reform in recent years. While there are big expectations of the reform, to the best of our knowledge no formal analysis of the expected implications of the changes to the pension system exists to date. We use our model to study the labor supply implications of the recent 
Swedish pension reform and to ask what particular aspects of the reform are driving the results. Our interest in Sweden is spurred by the unique nature of the large changes to social security, but also by some of the distinguishing country characteristics. Much of the existing literature on social security, particularly disability insurance claiming, has focused on the United States. Many of the institutional features in much of Europe, including Sweden, differ drastically from those in the United States. This is of course true of social insurance programs, but also of healthcare. Unlike the United States where many people receive health insurance through their employer, Sweden has a public healthcare system. The fact that Medicare eligibility in the United States starts at age 65 creates a potentially large incentive for people to continue working until then. This motive is absent in Sweden, and more broadly most of Europe.

Sweden is in the process of switching from a pay-as-you-go (PAYG), defined benefit program to a notional, pay-as-you-go, defined contribution plan. The first benefits from the new system were paid out in 2001. But due to the gradual phasing-in of the reform, not until 2040 will all benefits be paid from the new system. There are many issues inherent with the old Swedish pension system, key among them the fact that the pension benefit is based on earnings from only the 15 highest years and only income up to a relatively low ceiling counts toward the benefit. Not only does this have the potential to treat workers with equivalent lifetime earnings very unequally, it does not provide incentives for older individuals to remain employed. In fact, given that wages tend to level off in the 40s or 50s, there is no expected increase in pension benefits from continued employment for the majority of older workers. Furthermore, the system is sensitive to demographic change. One should also note that under the old system disability insurance is very generous. The new pension scheme hopes to address these issues.

We find that the Swedish pension reform creates large incentives for older workers to continue working longer. Our main findings are threefold: (1) the model predicts an increase in the average retirement age of 2.3 years from 62.4 to 64.7 , and (2) there is an increasing tendency for workers to continue working while collecting pension benefits, 
but (3) the fraction of older workers claiming disability insurance only declines by roughly one percentage point, from $18.6 \%$ to $17.7 \%$. To understand the results, consider the incentives for continued employment faced by someone of, say, age 65. Under the old pension system, the net present value of lifetime pension benefits was only marginally higher for someone who continued working past 65 than for someone who stopped at 65 . Under the new system, the net present value of lifetime pension benefits for someone that stops working at age 65 is lower than in the old system, but the net present value of lifetime pension benefits increases rather steeply from continued employment. An approximate calculation reveals that roughly $40 \%$ of the increase in the length of the average working life is due to the reduction in the generosity of pension benefits, while the remaining $60 \%$ are due to the increase in the present value of benefits from continued employment. Only a negligible share of the increase in aggregate labor supply is coming from a decline in disability insurance incidence. While the computation of the disability insurance benefit changes as part of the reform, we find that the net present value of lifetime benefits for someone that goes on disability insurance at, for example, age 50 is only slightly lower following the reform. This explains why the model does not predict a large change in disability insurance incidence.

There is a vast literature on retirement, pertaining to both the claiming of old-age pension benefits and disability insurance. Most of it is centered on the United States..$^{1}$ Methodologically, the paper most similar to ours is French (2005). There are several notable differences, however. In our framework individuals can impact the evolution of their health, whereas in French (2005) they cannot. Furthermore, our five tiers allow for a finer distinction between health categories than French's assumption of two health states, good and bad. Additionally, we allow for the possibility of individuals in poor health to go on disability insurance.

\footnotetext{
${ }^{1}$ See for example Gustman and Steinmeier (1986), Pozzebon and Mitchell (1989), Stock and Wise (1990), Berkovec and Stern (1991), Rust and Phelan (1997), French (2005), Gruber and Wise (2004), Gruber and Wise (2009), Coile and Gruber (2007), Coile and Levine (2007), Low, Meghir, and Pistaferri (2010), Laun (2011), French and Song (2009).
} 
Our paper also contributes to the literature on the impact of tax and transfer programs on life cycle labor supply. See, e.g., Rogerson and Wallenius (2009), Wallenius (2009). The key distinction between our paper and the aforementioned ones is that we are explicitly interested in disability insurance and as such also include endogenous health in our framework.

Jönsson, Palme, and Svensson (2011) document the prevalence of disability insurance incidence in Sweden, whereas Sundén (2006) and Palmer (2003) document the Swedish pension reform and its intended consequences. These papers are, however, descriptive in nature and do not provide any quantitative analysis of the policy reform. Sundén (2002) studies the ability of the post-reform Swedish pension system to adjust to demographic change. His analysis, however, assumes that retirement is exogenous.

An outline of the paper follows. Section 2 presents the model and the solution method, while Section 3 describes the calibration procedure. Section 4 outlines the quantitative exercise that is carried out in the paper and Section 5 describes the results from this exercise. Section 6 discusses the robustness of the results. Section 7 concludes.

\section{Model}

We consider a discrete time overlapping generations framework, in which a measure one of identical, finitely lived individuals is born every period. A model period is a year, and individuals live for 61 periods with certainty. Model age zero corresponds to age 20 in the data. Furthermore, individuals are endowed with one unit of time each period.

Letting $a$ denote model age, individuals have preferences over sequences of consumption $(c)$, labor supply $(l)$ and health $(h)$ given by:

$$
\sum_{a=0}^{60} \beta^{a}\left[\ln \left(c_{a}\right)-b\left(h_{a}\right) l_{a}+h_{a}\right]
$$

where $\beta$ is the discount factor. Preferences are assumed to be separable and consistent 
with balanced growth, thereby dictating the $\ln (c)$ choice. We assume that the disutility from working is health dependent. ${ }^{2}$ Specifically, working is more unpleasant the worse the health of an individual. Additionally, the health of an individual enters directly in the utility function.

Each period there are markets for consumption, labor, capital and health investment. Let $w_{a}$ denote the exogenous age-varying wage profile, $r$ the interest rate and $p(h)$ the cost of health investment as a function of health. The individual faces a sequence of budget constraints given by:

$$
c_{a}+k_{a+1}-(1+r) k_{a}+(1-s) p\left(h_{a}\right) i_{a}^{h}=(1-\tau) w_{a} l_{a}+I_{a}^{D I} D I_{a}+I_{a}^{P B} P B_{a}+T .
$$

The agent's capital stock at age $a$ is denoted by $k_{a}$. We impose a no-borrowing constraint, $k_{a} \geq 0$. This is one way of ensuring that people work when young, even at a low wage $\mathrm{H}^{3}$ Furthermore, we assume that individuals must have non-negative assets at death.

Health investments are denoted by $i_{a}^{h}$, and take the value of zero or one. Health investments are subsidized at the rate $s$. Following the OECD self-assessed health measure, health is discretized into five states: very good, good, fair, bad and very bad. All individuals start out in very good health. Health evolves according to the following law of motion:

$$
h_{a+1}=h_{a}+I_{a}^{H I} i_{a}^{h}+\varepsilon_{a}^{h}
$$

$I_{a}^{H I}$ is an indicator function, which takes the value one if the health investment is effective and zero otherwise. The probability that the health investment is effective is dependent on both the age and the health of the individual. $\varepsilon_{a}^{h}$ is the exogenous health shock. The probability of the health shock is also age- and health-dependent.

\footnotetext{
${ }^{2}$ This is an alternative to assuming that productivity, or the wage, is health dependent. Both result in a distribution of retirement ages. French (2005) finds that there is surprisingly little difference in the wages of healthy and unhealthy individuals. This observation appears to hold for Sweden as well.

${ }^{3}$ In the absence of a borrowing constraint, and with exogenous wages and individuals choosing the timing of work, people would choose not to work when young but rather at a higher wage later on. This is not what we observe in the data.
} 
We assume a discrete labor supply choice where the individual either works full-time or not at all, $l_{a} \in\{0, \bar{l}\}$. While for some individuals retirement is a gradual transition from full-time work to no work, for most this transition occurs abruptly. ${ }_{4}^{4}$ Assuming the presence of some non-convexity in the individual's choice problem is one way of generating movements from full time work to no work. Examples of non-convexities are fixed costs associated with work and non-linear wage schedules. Instead of modeling these underlying details, here we simply assume that individuals are faced with a discrete choice problem of full time work or no work. Labor income is the product of the exogenous, age-dependent wage and labor supply: $\left.\right|^{5}$ The government levies a proportional tax, $\tau$, on labor income.

$I_{a}^{D I}$ is an indicator function, which takes the value one if the individual claims disability benefits and zero otherwise. Similarly, $I_{a}^{P B}$ is the indicator function associated with pension benefits. $D I_{a}$ denotes the disability benefits and $P B_{a}$ the pension benefits. Both benefits depend on the age and past earnings of the claimant, and in the case of disability benefits, on health. The benefits will be discussed in more detail in the calibration section. $T$ denotes a lump-sum transfer, which is the same for all individuals.

The government uses the proceeds from the proportional tax levied on labor income, $\tau$, to finance the subsidy on health investment, pension and disability insurance benefits, as well as the lump-sum transfer. We assume a balanced budget in equilibrium. ${ }^{6}$

\subsection{Solving the Model}

Each period an individual must choose: how much to consume, how much to invest in physical capital, whether or not to invest in health, whether or not to work, whether or not to apply for disability insurance and whether or not to apply for pension benefits. The

\footnotetext{
${ }^{4}$ See Rogerson and Wallenius (2011) for a discussion of the United States. The same observation is true for Sweden. We return to this point in Section 3

${ }^{5}$ We assume that the price per efficiency unit of labor has been normalized to one.

${ }^{6}$ We consider alternatives to the lump-sum transfer in Section 6.
} 
large number of combinations implies a large state space. This in turn yields a computationally intensive problem.

As labor supply and health investment are discrete choices by construction, we only need to discretize physical capital. We assume a capital grid with 31 grid points, ranging from 0 to 1500000 SEK (roughly 227000 USD).

We solve for decision rules via backward induction. Assuming zero utility when dead, we know the value function at age 81 . This allows us to solve the agent's problem at age 80 for each possible employment history, consisting of disability, pension and retirement decisions, and for each state of health and physical capital. We then know the value function at age 80 and can solve the agent's problem at age 79 and so on.

Having solved for the decision rules, we simulate the model 61000 times. For aggregation purposes we assume that at any given point in time, the economy consists of 10 00020 year olds, 1000021 year olds, 1000022 year olds, and so forth. All agents start out with zero capital and in very good health.

\section{Calibration}

In this section we discuss the approach for assigning parameter values. Recall that a model period is a year, and that agents enter the model at age 20 . We assume that the initial capital stock of an individual is zero.

The policy parameters are chosen to match the Swedish pre-reform social security system. The remaining parameters are chosen to match various moments of the Swedish data. We now describe this process in greater detail.

The preference parameters needing to be assigned a value are the discount factor, $\beta$, and the disutility from working parameter, $b(h)$. We target an annual interest rate of $3 \%$, and simply assume that $\beta=1 /(1+r) \cdot 7$ The disutility from working is larger, the worse

\footnotetext{
${ }^{7}$ Relaxing this assumption would introduce life-cycle effects in the consumption profile. While there is
} 
the health status of an individual. We assume a linear relationship between the disutility levels associated with the five discrete health states and parameterize it so as to target the retirement age distribution. See Figure 1 for an illustration of the target distribution. 8

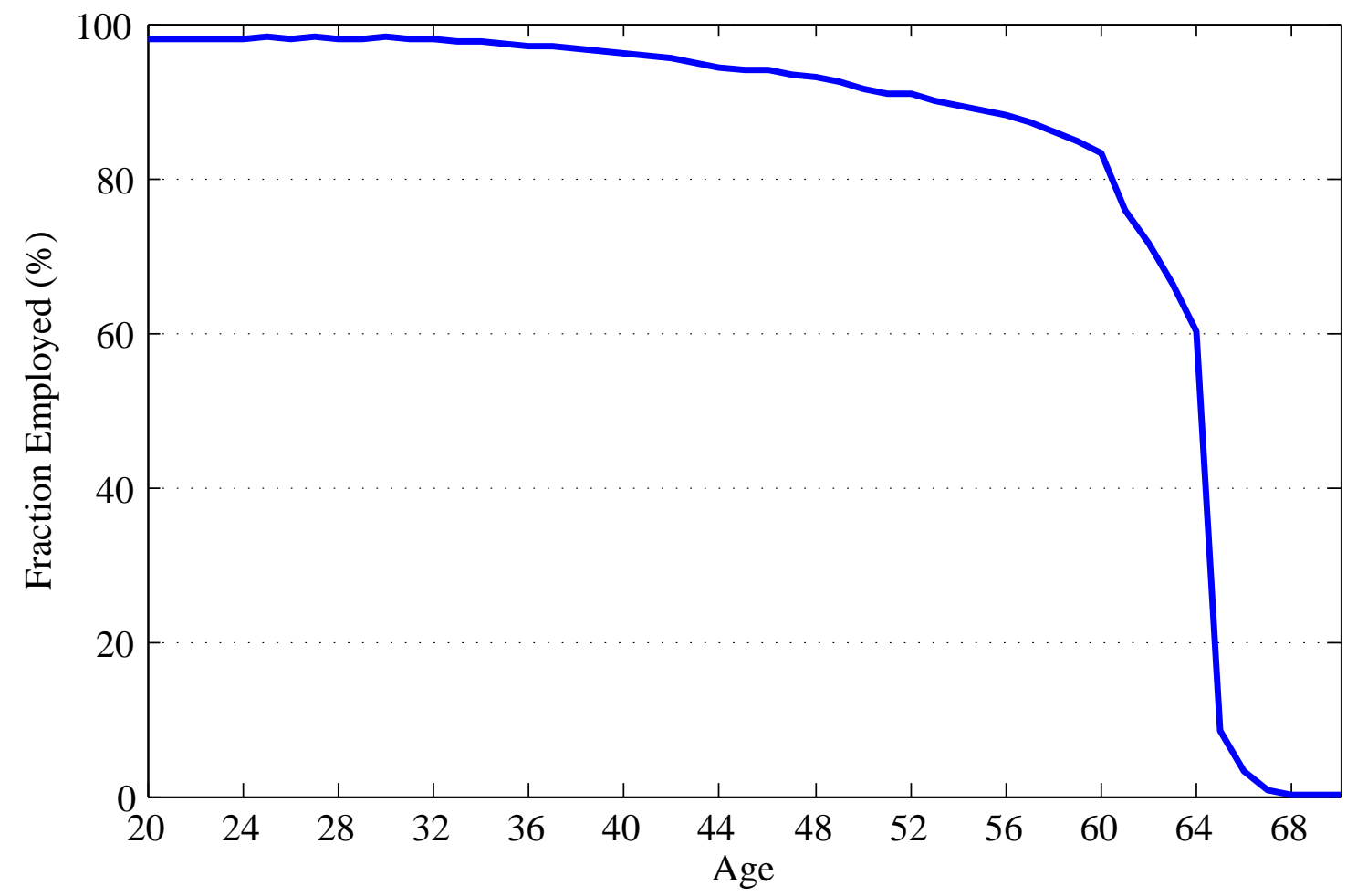

Figure 1: Fraction Employed by Age. Data source: Swedish Pension Authority, 2009.

The exogenous age-varying wage profile is constructed from Eurostat data for the year 2009. The data reports average labor income for five-year age bins, 18-24, 25-29, $30-34,35-39,40-44,45-49,50-54,55-59$, and $60-64$. We fit a quadratic function to the data and use that to interpolate values for individual ages. Figure 2 plots this function. It exhibits the typical hump-shaped profile, with income leveling out in the 40s and 50s and declining slightly in the $60 \mathrm{~s} .9$

We assume an indivisible labor supply choice, where people either work a fixed worksome empirical evidence of this, these effects are not of first-order importance for the questions addressed here. We have, therefore, chosen to abstract from them.

${ }^{8}$ Due to classification issues by the Swedish pension authority based on pension collection these numbers may exclude some people who are working. Therefore the values constitute a lower bound of employed people.

${ }^{9}$ The results are robust to adjusting the labor earnings profile by average hours for each particular age group. At older ages, there are issues associated with selection. We return to this point in Section 6 


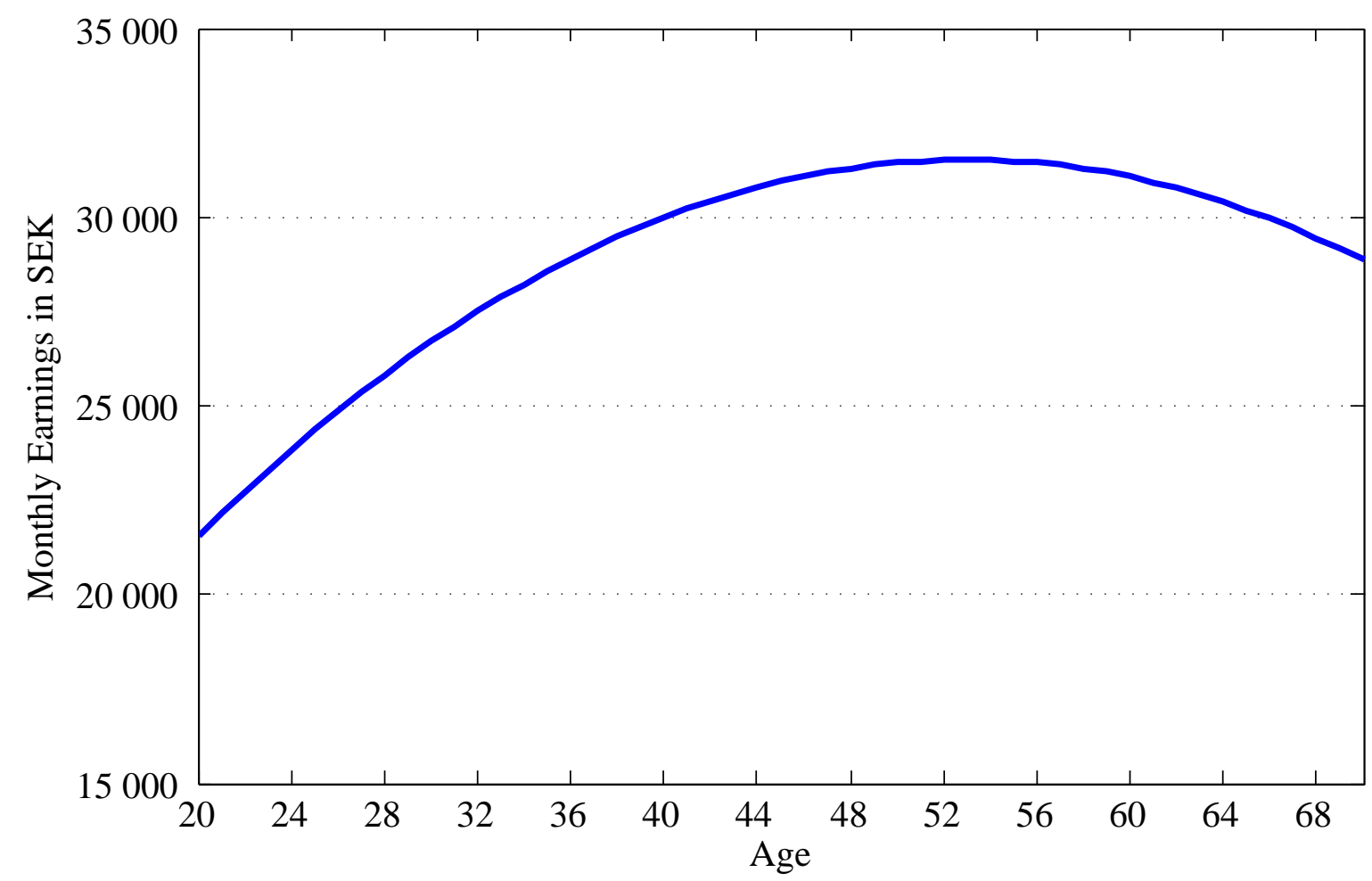

Figure 2: Average Earnings Profile. Data source: Eurostat, 2009.

week or not at all. The length of the workweek is set to $1 / 3$ of the time endowment. Given our emphasis on retirement, the nature of the transition from full-time work to little or no work is particularly relevant. As depicted in Figure 3, at age 55, more than $60 \%$ of Swedes are working full-time (35 hours or more per week), whereas $20 \%$ are not working at all. At age 70, virtually no one is working. The SHARE ${ }^{10}$ dataset is not a panel, and therefore does not preclude the fact that some people could be transiting sequentially between hours bins. The fact that the fraction of the age group working part-time (between 10 and 25 hours per week) stays roughly constant at $10 \%$ until it drops to essentially zero at age 65, however, suggests that that this is very limited in scope. Moreover, the low

\footnotetext{
${ }^{10}$ This paper uses data from SHARELIFE release 1, as of November 24th 2010. The SHARE data collection has been primarily funded by the European Commission through the 5th framework program (project QLK6-CT-2001-00360 in the thematic program Quality of Life), through the 6th framework program (projects SHARE-I3, RII-CT-2006-062193, COMPARE, CIT5-CT-2005-028857, and SHARELIFE, CIT4-CT-2006-028812) and through the 7th framework program (SHARE-PREP, 211909 and SHARELEAP, 227822). Additional funding from the U.S. National Institute on Aging (U01 AG09740-13S2, P01 AG005842, P01 AG08291, P30 AG12815, Y1-AG-4553-01 and OGHA 04-064, IAG BSR06-11, R21 AG025169) as well as from various national sources is gratefully acknowledged (see www.share-project.org for a full list of funding institutions).
} 
incidence of part-time work leads one to conjecture that part-time work is not very desirable in Sweden, be it due to a limited availability of part-time jobs or a wage penalty associated with them. We therefore feel that the inclusion of a part-time work option is not of first-order importance for our analysis.

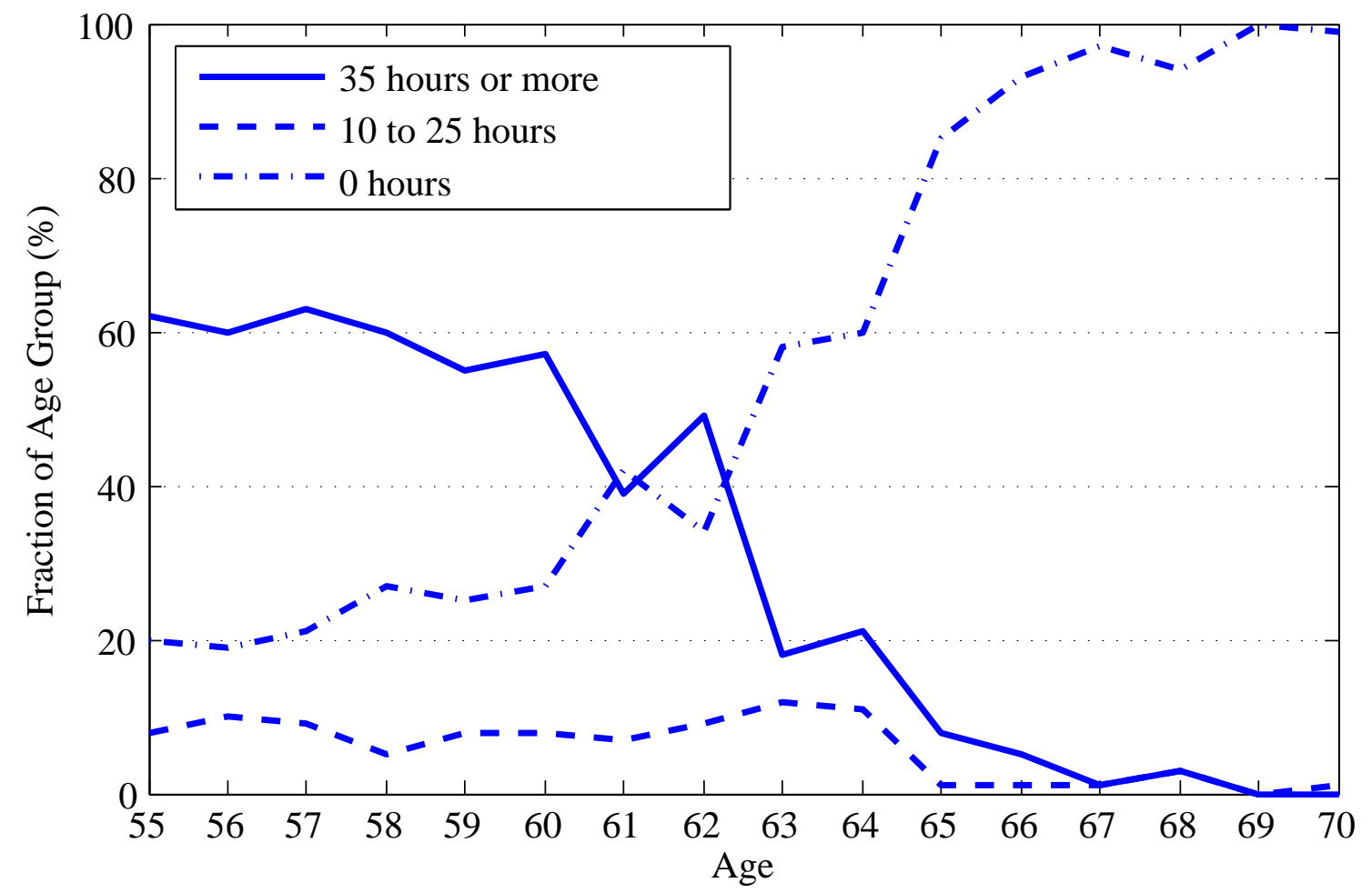

Figure 3: Incidence of Full-Time vs Part-Time Work by Age. Data source: SHARE.

Pertaining to health, three objects need to be parameterized: the cost function for health investments, the process governing the effectiveness of health investments and the process governing shock to health. With the cost function for health investment we wish to capture both the overall level of health expenditures and the differences in health expenditure by health status. Our measure for health expenditures is from the Survey on Health, Aging and Retirement in Europe (SHARE) and is the sum of expenditures on inpatient care, outpatient care, prescription drugs and health insurance. The appealing feature of the SHARE data is that it is possible to tabulate average health expenditures by health status. The health expenditure measure in this dataset, however, is an incomplete measure of health expenditures and captures just over $50 \%$ of all health expenditures in 
Sweden. Our approach, therefore, is to use the SHARE data to capture the differences in health expenditure by health status and to set the level of health costs so as to match total health expenditures as a fraction of total tax revenue. In Sweden, total health expenditures constitute roughly $18 \%$ of total tax revenue.

We assume two possible shocks to health, a small shock and a big shock. The small shock constitutes a one-unit drop in health, whereas the big shock constitutes a three-unit drop in health. Given that health investment is at most one, and not always effective, agents can only partially insure against health shocks. The probability of health shocks is increasing in age. Furthermore, the probability of being hit by a shock is bigger, the worse ones health. This feature is included to mimic persistence in health. The probability that the health investment is effective is decreasing in age. Also, the probability that the investment is effective is lower, the worse the health of the individual. The probabilities of the health shocks and the probabilities governing the effectiveness of health investments are chosen to target the fraction of people on disability insurance, the timing of disability incidence and the health distribution at older ages. Table 1 reports the fraction of each age group on disability insurance. Disability insurance incidence is quite high in Sweden, with $18.6 \%$ of the population going on disability insurance at some point during their life. The majority of disability insurance incidence occurs after the age of 50 .

\begin{tabular}{cc}
\hline \hline Age & Fraction on DI \\
\hline \hline $20-24$ & 0.02 \\
$25-29$ & 0.02 \\
$30-34$ & 0.02 \\
$35-39$ & 0.03 \\
$40-44$ & 0.04 \\
$45-49$ & 0.06 \\
$50-54$ & 0.09 \\
$55-59$ & 0.12 \\
$60-64$ & 0.18 \\
\hline \hline
\end{tabular}

Table 1: Fraction on Disability Insurance by Age. Data source: Swedish pension authority, 2009.

Table 2 reports self-assessed health states for older individuals. The reported values 
are expressed as a fraction of the relevant age group. In the model we assume that an individual must be in either bad or very bad health to be eligible for disability insurance.

\begin{tabular}{cccccc}
\hline \hline Age & Very good & Good & Fair & Bad & Very bad \\
\hline \hline 55 to 64 & 29.9 & 35.1 & 24.5 & 7.7 & 2.9 \\
65 to 74 & 25.0 & 40.4 & 27.0 & 5.9 & 1.7 \\
75 to 84 & 15.7 & 33.5 & 35.4 & 10.6 & 4.8 \\
\hline \hline
\end{tabular}

Table 2: Self-Assessed Health by Age (reported as percentage of age group). Data source: OECD, 2009.

Sweden has a public healthcare system. We capture this in an extremely stylized way, by assuming a subsidy on all health investments. The rate of the subsidy is set to match public spending as a fraction of total spending on healthcare. This share is $81.9 \%$ for Sweden.

The tax on labor income is set to equal the average effective labor tax burden in Sweden in 2009. The tax rate of 0.438 includes income taxes, payroll taxes and consumption taxes. ${ }^{11}$ Recall that the labor tax is used to fund the subsidy on health investment, pensions, disability insurance and the lump-sum transfer. We assume the government balances its budget in equilibrium; the lump-sum transfer is set so as to accomplish this.

The model is calibrated to the pre-reform Swedish pension system. It is a PAYG, defined benefit plan financed through a payroll tax. The pension benefit is comprised of two parts, a basic allowance and an earnings dependent supplement. Both are tied to the so-called basic amount (BA), which equaled 43600 SEK (roughly 6600 USD) in 2009. The basic allowance is the same for everyone and equal to 0.96BA. The earnings dependent supplement is given by:

$$
0.6 A P_{a} \min (a / 30,1) \mathrm{BA},
$$

where $A P_{a}$ is average pension points at age $a$. One accrues pension points from earned

\footnotetext{
${ }^{11}$ The method for computing tax rates is outlined in McDaniel (2007). The actual tax series can be found at http://www.caramcdaniel.com/researchpapers.
} 
income in the 15 highest years of earnings. They are computed by taking income in excess of the BA up to 7.5BA and dividing by the BA. Furthermore, there is an adjustment when there are less than 30 years of work.

When mapping this to the model, average pension points are a state variable. The state variable is updated according to the following rule:

$$
\begin{array}{ll}
A P_{a+1}=A P_{a}+\frac{1}{15} \frac{\min \left\{w_{a} \bar{l}, 7.5 \mathrm{BA}\right\}-\mathrm{BA}}{\mathrm{BA}} & \text { if } \quad a<15 \\
A P_{a+1}=A P_{a}+\frac{1}{15} \max \left\{0, \frac{\min \left\{w_{a} \bar{l}, 7.5 \mathrm{BA}\right\}-\mathrm{BA}}{\mathrm{BA}}-A P_{a}\right\} & \text { if } \quad a \geq 15 .
\end{array}
$$

In other words, if the individual has worked for less than 15 years, an additional year of work always increases average pension points. If the individual has worked for 15 or more years, average pension points only increase if earnings exceed average earnings to date. We make the simplifying assumption that a high income year replaces an average income year, instead of the lowest income year. This is the same as in French (2005).

The first age at which the pension benefit can be claimed is 61 . The full retirement age is 65 . The actuarial adjustment for early claiming is $0.5 \%$-points for every month up to age 65 . The actuarial adjustment for delayed claiming is $0.7 \%$ for every month up to age 70 .

The disability insurance benefit is computed in much the same way as the pension benefit. The notable exceptions are: (1) there is no actuarial reduction for early claiming, (2) assumed pension points are computed up to age 65 based on average income from the last three years prior to disability. These features make disability insurance under the old rules very generous. People are automatically transferred from disability insurance to regular pension at the age of 65 . The benefit stays the same throughout.

If one experiences only a partial loss in earnings capacity, it is possible to claim partial disability insurance in Sweden. As roughly three-quarters of all disability claimants are on full-disability insurance, we abstract from partial disability insurance in our model. It 
is not possible to continue working while on full-disability insurance. In the model, we assume that the individual must be in bad or very bad health to qualify for disability insurance. We arrived at this cut-off after examining data on the self-reported heath status of older workers, as well as the fraction of the age group on disability insurance. According to the Swedish pension authority (Pensionsmyndigheten), the fraction of people aged 5564 on disability insurance in Sweden in 2009 was roughly $16 \%$. According to the OECD self-assessed health questionnaire, of this same age group roughly $11 \%$ reported being in bad or very bad health. We assume that if the individual satisfies this health criterion, and applies for disability, he/she receives it ${ }^{12}$ Furthermore, we assume that disability is an absorbing state.

Table 3 summarizes the benchmark calibrated parameter values for the model.

A brief explanation of a few of the listed parameters is in order. As previously noted, the disutility from working is greater the worse the health of the individual. We assume a linear relationship. The table reports the two boundary points.

The probability of being hit by the small health shock increases linearly with age from 0.1 to 0.5 . However, if the individual is in the worst health state, the probability of being hit by the small shock is 0.5 , regardless of age. The probability of the big health shock is constant over age at 0.01 , unless the individual is in the worst health state, in which case the probability is 0.1 . As noted previously, the dependency of the shock probability on health status mimics persistence.

Recall that the probability that the health investment is effective is dependent on both age and health. Given a particular level of health, the probability that health investment is effective decreases linearly with age. A decline in health, however, shifts the probabilities to a lower trajectory. The table reports the boundary values for each health state.

\footnotetext{
${ }^{12}$ Alternatively we could assume that a person applying for disability insurance receives the benefit with some positive probability, and that this probability is bigger, the worse the health of the applicant. The reason we decided not to pursue this option is that it would require the determination of several parameter values, of which we have little way of knowing how to discipline.
} 


\begin{tabular}{|c|c|c|}
\hline Parameter & Value & Explanation \\
\hline \multicolumn{3}{|c|}{ Policy Parameters } \\
\hline$\tau$ & 0.438 & Tax on labor income \\
\hline$s$ & 0.82 & Subsidy on health expenditure \\
\hline \multicolumn{3}{|c|}{ Utility Parameters } \\
\hline$\beta$ & 0.97 & Discount factor \\
\hline$b_{5}$ & 2.5 & Disutility from work when health very good \\
\hline$b_{4}$ & 3.0 & Disutility from work when health good \\
\hline$b_{3}$ & 3.5 & Disutility from work when health fair \\
\hline$b_{2}$ & 4.0 & Disutility from work when health bad \\
\hline$b_{1}$ & 4.5 & Disutility from work when health very bad \\
\hline $\bar{l}$ & $\frac{1}{3}$ & Labor supply \\
\hline \multicolumn{3}{|c|}{ Health Parameters } \\
\hline$e^{l}$ & 1 & Decrease in health from low shock \\
\hline$e^{h}$ & 3 & Decrease in health from high shock \\
\hline$p^{l}$ & $0.1 \rightarrow 0.5$ & Probability of low shock \\
\hline$p_{1}^{l}$ & 0.5 & Probability of low shock when health very bad \\
\hline$p^{h}$ & 0.01 & Probability of high shock \\
\hline$p_{1}^{h}$ & 0.1 & Probability of high shock when health very bad \\
\hline$q_{5}$ & $1 \rightarrow 0.5$ & Probability health investment effective when health very good \\
\hline$q_{4}$ & $0.9 \rightarrow 0.5$ & Probability health investment effective when health good \\
\hline$q_{3}$ & $0.8 \rightarrow 0.5$ & Probability health investment effective when health fair \\
\hline$q_{2}$ & $0.4 \rightarrow 0.1$ & Probability health investment effective when health bad \\
\hline$q_{1}$ & $0.2 \rightarrow 0.1$ & Probability health investment effective when health very bad \\
\hline
\end{tabular}

Table 3: Calibrated Parameter Values

\subsection{Calibrated Economy}

We now outline the calibrated economy and discuss how well we are able to match the data on Sweden prior to the pension reform.

Figure 4 plots the distribution of retirement ages for the benchmark economy relative to the data. From the figure one notes that the timing of retirement predicted by the model mimics that in the data quite closely. In particular, the model predicts first a gradual decline in employment rates in the early 60s followed by a sharper decline in the mid 60s. The average age at which people stop working in the benchmark economy is 62.4 . Given that pension claiming does not require that one stop working, there is no reason to expect that the age at which people stop working would coincide with the age at which they start 


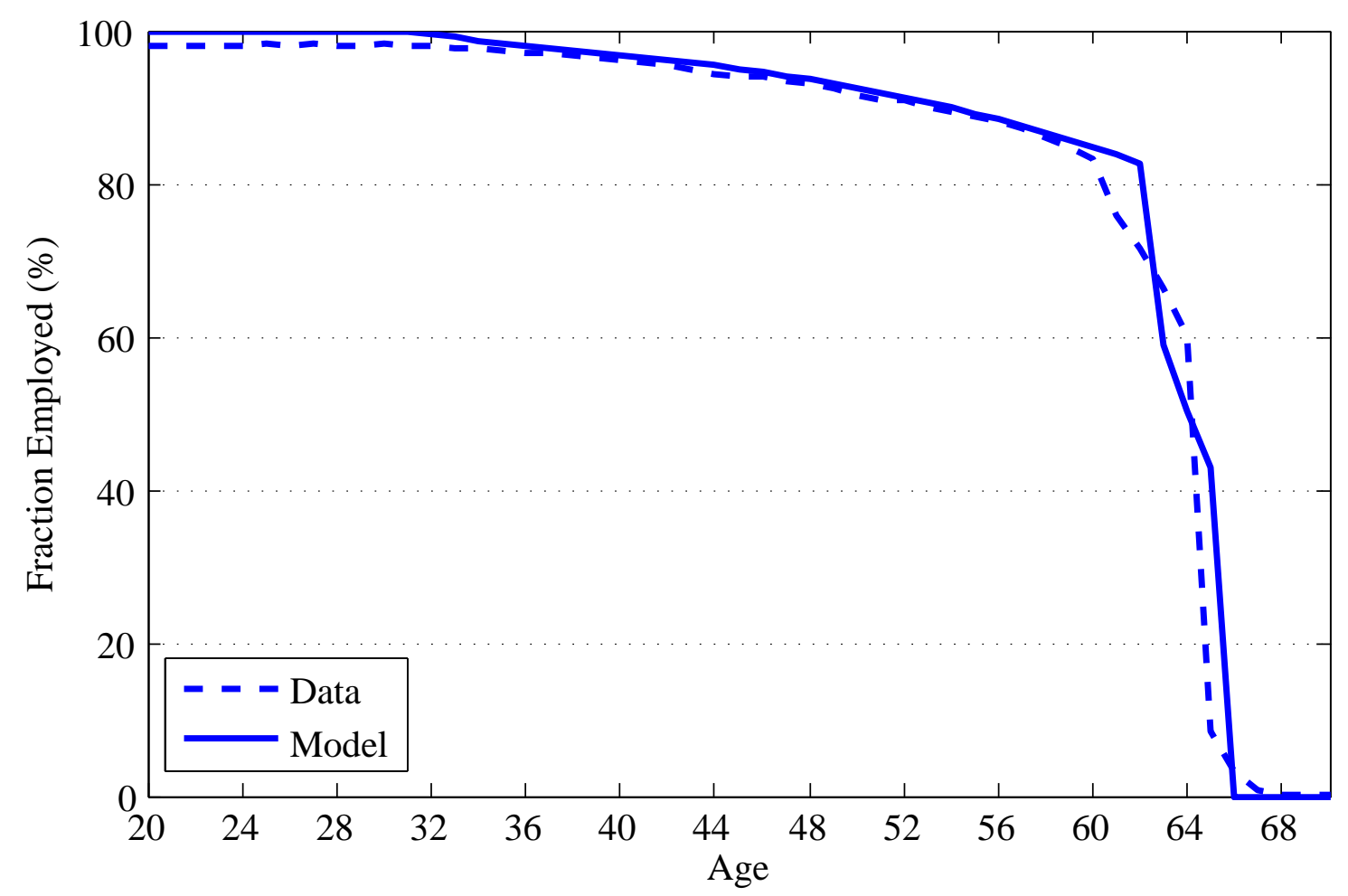

Figure 4: Fraction Employed by Age

collecting pension benefits. Moreover, the adjustments for early and delayed claiming are roughly actuarially fair. With certain lifetimes, the agents are then rather indifferent about when to start taking out benefits. In the model, everyone (who does not go on disability insurance) starts collecting pension benefits at age 63. For the purposes of any policy analysis, the age at which people stop working is of more interest than the age at which they start collecting pension benefits. In contrast to pension benefits, to claim disability benefits one must stop working.

Figure 5 plots the fraction of a particular age group that is on disability insurance. The solid line denotes the model predicted values, while the dashed line sketches the data. The model does a relatively good job of matching both the incidence and timing of disability insurance. The model predicts that $18.6 \%$ of people go on disability insurance during their lifetime. The average age at which people claim disability benefits in the model is 51.3. Note that the last age at which people are eligible for disability is 64 ; at age 65 disabled individuals are automatically transferred to pension. 


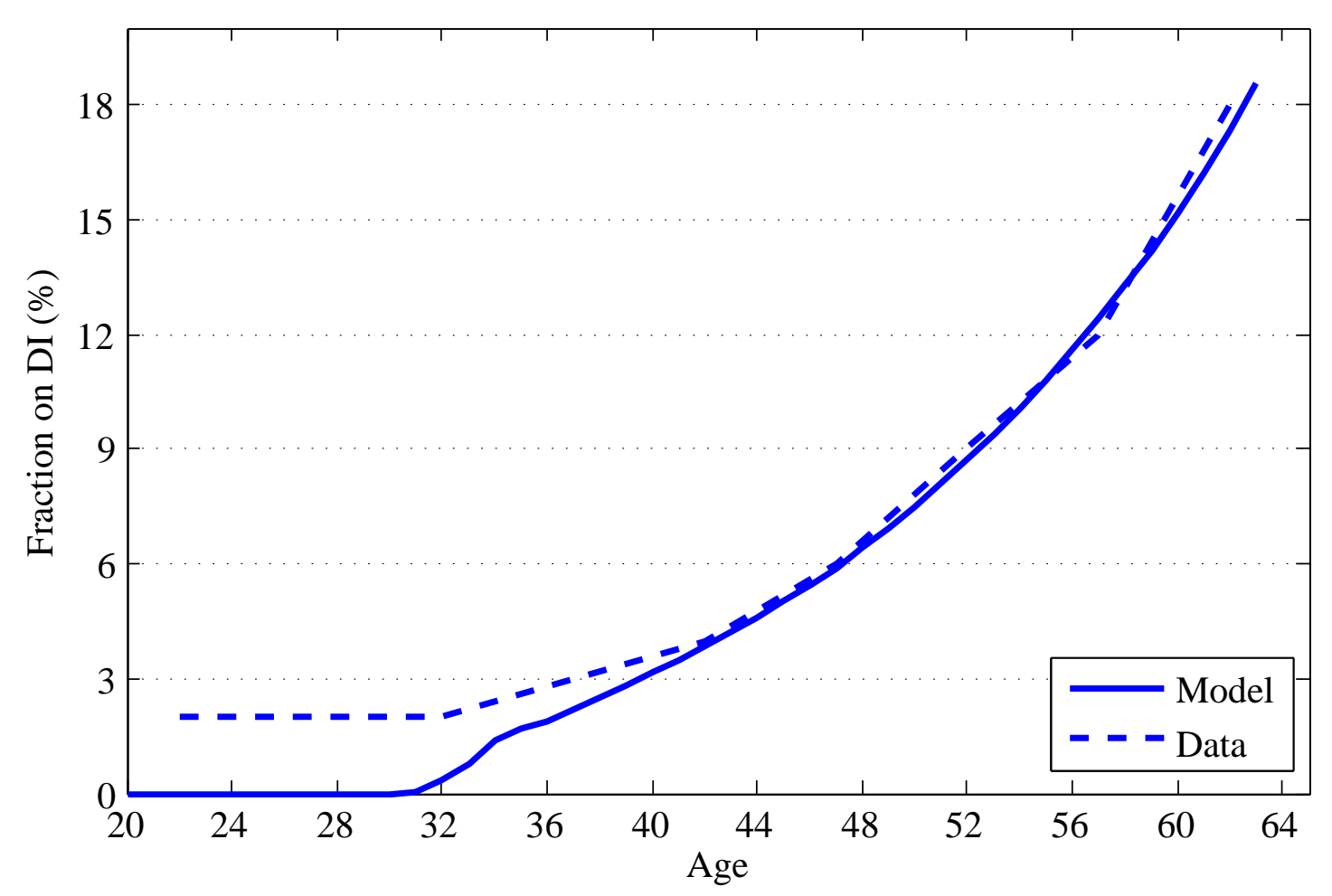

Figure 5: Fraction on Disability Insurance by Age.

One aspect of the data that the model struggles to match is the health distribution at older ages. To illustrate, the model predicts that at age 70: 47\% of people are in very good health, $21 \%$ in good health, $8 \%$ in fair health, $5 \%$ in bad health and $19 \%$ in very bad health. In contrast, according to the data on people aged $65-74,25 \%$ are in very good health, $40.4 \%$ in good health, $27 \%$ in fair health, $5.9 \%$ in bad health and $1.7 \%$ in very bad health 13 The health distribution predicted by the model places too little mass at intermediate health states. There is tension in the model between matching the fraction of people on disability insurance and matching the health distribution at older ages. We feel that matching the fraction of people on disability insurance is more important for the policy analysis to follow.

Note also that in our model the majority of people who go on disability insurance, and thereby satisfy the poor health criterion, stay in poor health throughout the remainder of their life.

\footnotetext{
${ }^{13}$ The OECD self-assessed health data is only available for 10 -year age bins.
} 
The tax rate on labor income is $43.8 \%$ and the budget balancing lump-sum transfer is 28000 SEK (roughly 4200 USD) per person annually. The ratio of total health expenditures to total tax revenue in the calibrated economy is $18.6 \%$. This is very close to the $18 \%$ reported in the data.

To summarize, the model does a good job of replicating the salient features of the prepension reform Swedish economy, particularly as it pertains to the labor supply behavior of older workers.

\section{Quantitative Exercise: Pension Reform}

We now analyze the implications of the recent Swedish pension reform. This entails modifying the pension and disability insurance schemes to reflect the new policies. All other parameters are as in the benchmark calibration. Specifically, we assume a small open economy with a fixed interest rate and price per efficiency unit of labor. The effective labor tax burden has stayed roughly constant in recent years. We therefore keep $\tau$ fixed at 0.438 , but compute a new budget balancing lump-sum transfer ${ }^{14}$

The new pension scheme is comprised of two parts, a notional defined contribution component and a funded individual account. The contribution rate is $18.5 \%$ on all earnings, of which $16 \%$ are credited to the defined contribution part and $2.5 \%$ to the individual accounts. Pension rights are accrued on earnings up to a ceiling, which equaled 50900 SEK in 2009 (roughly 7700 USD). The annuity is then computed by taking total pension capital and dividing by life expectancy.

The system is still a PAYG system, with current contributions used to fund the benefits of the current old. The size of the benefit is dependent on current economic conditions. This is why the benefit scheme is classified as a notional defined contribution plan.

The first age at which one can collect pension benefits is unchanged at 61 . If one con-

\footnotetext{
${ }^{14}$ We discuss the implications of keeping the transfer fixed at the pre-reform level in Section 6 .
} 
tinues to work while collecting pension benefits, one continues to accrue pension capital. The benefit is then recalculated when the individual stops working.

The computation of the disability insurance benefit has also changed as part of the reform. Under the new system, the disability benefit is equal to $64 \%$ of the average income from the three years prior to disability. One accrues pension benefits while on disability. Also, as was the case prior to the reform, people are automatically transferred from disability insurance to pension at age 65 .

When modeling the pension reform, we don't explicitly model the funded accounts component and instead treat all contributions as if they were part of the defined contribution part. In Section 6 we consider an alternative to this, namely treating the funded accounts component as purely forced savings. This entails lowering the labor tax rate by 2.5 percentage points.

\section{Results}

There are several issues inherent with the old Swedish pension system, in particular the fact that the pension benefit is based on earnings from only the 15 highest years and only income up to a relatively low ceiling counts toward the benefit. This has the potential to treat workers with equivalent lifetime earnings very unequally, as someone with low income in many years would earn significantly less than someone with the same lifetime income concentrated in 15 years. Furthermore, it does not provide incentives for older individuals to remain employed. In fact, given that wages tend to level off in the 40s or $50 \mathrm{~s}$, there is no expected increase in pension benefits from continued employment for most older workers. The new pension scheme hopes to address this issue.

In this section we discuss the implications of the pension reform as predicted by the model. We are particularly interested in whether the reform creates incentives for people to continue working longer. 


\subsection{Timing of Retirement}

We find that the Swedish pension reform does indeed create large incentives for workers to remain employed longer. In fact, the model predicts an increase in the average retirement age of 2.3 years from 62.4 to 64.7. Figure 6 illustrates the shift in the overall retirement age distribution. Following the reform, a notable number of people are predicted to still be working at ages $66-68$.

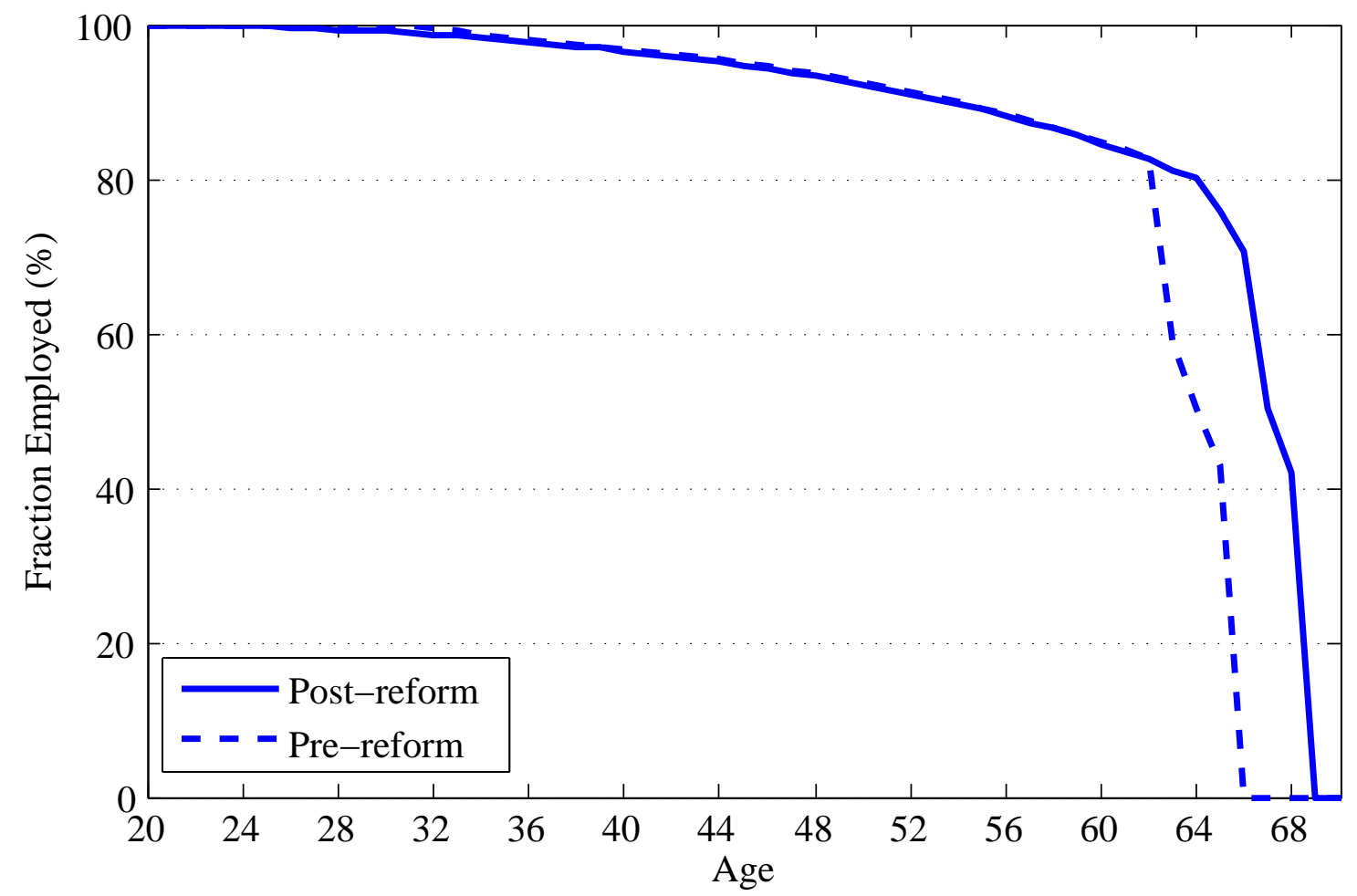

Figure 6: Fraction Employed by Age

Following the changes to the Swedish pension system, there is an increasing tendency for workers to continue working while collecting pension benefits. According to the model people take out pension benefits earlier than before, with the majority of people now taking out pension benefits starting at age 61, compared with age 63 in the old system.

The Swedish pension reform changes the computation of pension benefits along several dimensions. In terms of understanding the results, two features are of paramount 
importance. They are the reduction in the generosity of benefits (holding the stop working age constant) and the increase in benefits from deferred retirement. In the old system the net present value of lifetime pension benefits as a function of the age at which one stops working is very flat. In the new system this schedule rises much more steeply as a function of the age at which one stops working. However, were one to stop working at the same age in the new system as in old system, the present value of lifetime benefits would be lower. To disentangle these two effects, consider the following simple exercise. Compute the sum of the present value of lifetime pension benefits for everyone in the old system, given their optimal retirement choices. Then compute the hypothetical benefits from the new system if people were to stop working at the same age as in the old system. This calculation indicates that total lifetime benefits in net present value terms are about $90 \%$ of their previous level in the new system. We then uniformly scale down the prereform pension scheme by a factor of $0.903 \sqrt{15}$ Following this reduction in the scale of pension benefits, the average retirement age rises by roughly one year. This approximate exercise indicates that roughly $40 \%$ of the predicted increase of 2.3 years in the average retirement age resulting from the pension reform is due to the reduction in the generosity of benefits, whereas the remaining $60 \%$ is due to the fact the the present value of lifetime pension benefits increases when one defers retirement.

\subsection{Disability Insurance Incidence}

In response to the changes to social security, the model predicts that the fraction of older workers claiming disability insurance falls by roughly 1 percentage point, from $18.6 \%$ to 17.7\%. This implies that only a small fraction of the increase in employment is coming from a decline in the incidence of disability insurance.

All disability claimants are automatically transferred into pension at age 65 . This is true of both the old and the new system. In the old system, however, this distinction was

\footnotetext{
${ }^{15}$ The calculation of the scale factor assumes that the collection of pension benefits in each system starts when it is optimal. This is independent of the age at which one stops working.
} 
irrelevant from the individual's perspective, as the benefit was constant. This is no longer the case in the new system. The disability insurance benefit is actually somewhat higher in the new system, but the expected pension benefit is lower for someone who has been on disability for an extended amount of time, compared with that in the old system. The reason for this is that one continues to contribute to pension capital when on disability insurance, but at a significantly lower rate than when working. These two opposing effects roughly offset for someone who claims disability insurance at the average age for disability incidence. In other words, the net present value of lifetime benefits for someone that goes on disability insurance under the new system at, say age 50, is only slightly lower than for someone who did the same under the old system. Given that the economic incentives for disability insurance claiming change very little as a result of the pension reform, it is not surprising that the model does not predict a more significant decline in disability insurance incidence following the reform.

The average age for going on disability insurance declines by roughly one year following the reform, from 51.30 to 49.98 . This is explained by the fact that the present value of lifetime disability and pension benefits (for someone who goes on disability insurance) is higher in the new system than in the old system when one claims benefits before age 50 , but lower when one claims later.

\subsection{Other Implications}

One of the additional concerns with the old Swedish social security system was the heavy financial burden the funding of the system placed on taxpayers. In our model, the decline in the share of tax revenue going to fund pensions following the reform is exemplified by the increase in the lump-sum transfer. All else equal, our model predicts an increase in the lump-sum transfer from 28000 SEK to 36000 SEK (from 4200 USD to 5400 USD) needed to balance the budget subsequent to the changes in social security programs. As previously mentioned, we explore alternatives to this model assumption in the following 
section.

Health expenditures as a fraction of tax revenue are virtually unchanged at $17.6 \%$, previously $18.6 \%$. Similarly, the health distribution is also unchanged by the reform.

\section{Sensitivity Analysis}

In this section we discuss the robustness of the results to various features of the model and the data.

One key issue in matching a wage or labor income profile is that we only observe wages for those who work. The problem of selection is particularly relevant at older ages. As a robustness check we re-calibrate the model to a wage profile where wages after age 62 are kept constant at the age 62 level. Comparing the model predicted postpension reform retirement age distributions for the two specifications, one notes that there is slightly more mass retiring at ages 68 and 69 when wages are assumed constant after age 62 than when they were allowed to decline. Overall, however, the effect is negligible, with the model now predicting an average retirement age of 64.8 for the post-reform pension system, compared with 64.7 in the baseline calibration.

As previously noted, the Swedish pension reform implies a decline in the tax revenue needed to fund social security. Given that the labor tax rate has not declined following the reform, the assumption of budget balancedness in the model implies an increase in the lump-sum transfer. Alternatively, one could ignore this general equilibrium aspect and only consider the partial equilibrium decision problem of agents. This would entail keeping the lump-sum transfer fixed at the pre-reform level. This results in a small shift in the post-reform retirement age distribution, with some of the people previously retiring at age 67 choosing to defer retirement until age 68 or 69 . The aggregate effect is to raise the average retirement age in the post-reform economy from 64.7 to 65 . This in turn implies that the partial equilibrium version of the model implies an increase in the average 
retirement age of 2.6 years following the Swedish pension reform, compared with the 2.3 years predicted by the general equilibrium version.

Recall that when modeling the Swedish pension reform we abstract from the fully funded component and treat all contributions as part of the defined benefit component. The funded component is a form of forced savings. Given that one could reduce other savings by a corresponding amount, one could in fact argue that it isn't really different from regular savings. Assuming agents are cognizant of this, this suggests lowering the labor tax rate by the size of the funded component, i.e., 2.5 percentage points, when going from the old pension scheme to the new one. When modeled this way, the labor supply implications of the Swedish pension reform are even larger than when treating all contributions as part of the defined benefit portion. Figure 7 depicts the retirement age distribution for this case, and contrasts it with the retirement age distributions for the old pension system and the new system when treating all contributions as part of the defined benefit component. The average retirement age rises to 65.5 . This corresponds to an increase in the average retirement age of 3.1 years relative to the old pension system, compared with our baseline prediction of an increase of 2.3 years.

In our analysis we set the labor tax rate to match the average effective labor tax burden in Sweden. Although pension and disability insurance benefits and healthcare expenditures constitute a large share of government expenditures, we are required to take a stand on what to do with the additional tax revenue in the model. The results presented in this section and the previous one have assumed a lump-sum transfer of equal size to all individuals. There are many alternatives to the assumption of a lump-sum transfer, and following Rogerson (2007) and Ragan (2005) we know that the labor supply implications of labor taxes can be quite different depending on what the government does with the tax revenue. As a robustness check, we set the lump-sum transfer to zero and instead assume that the tax revenue that is left over after pension and disability insurance payments and healthcare subsidies is spent on government consumption. We assume that the individual values government consumption but that it enters separately in the utility function. 


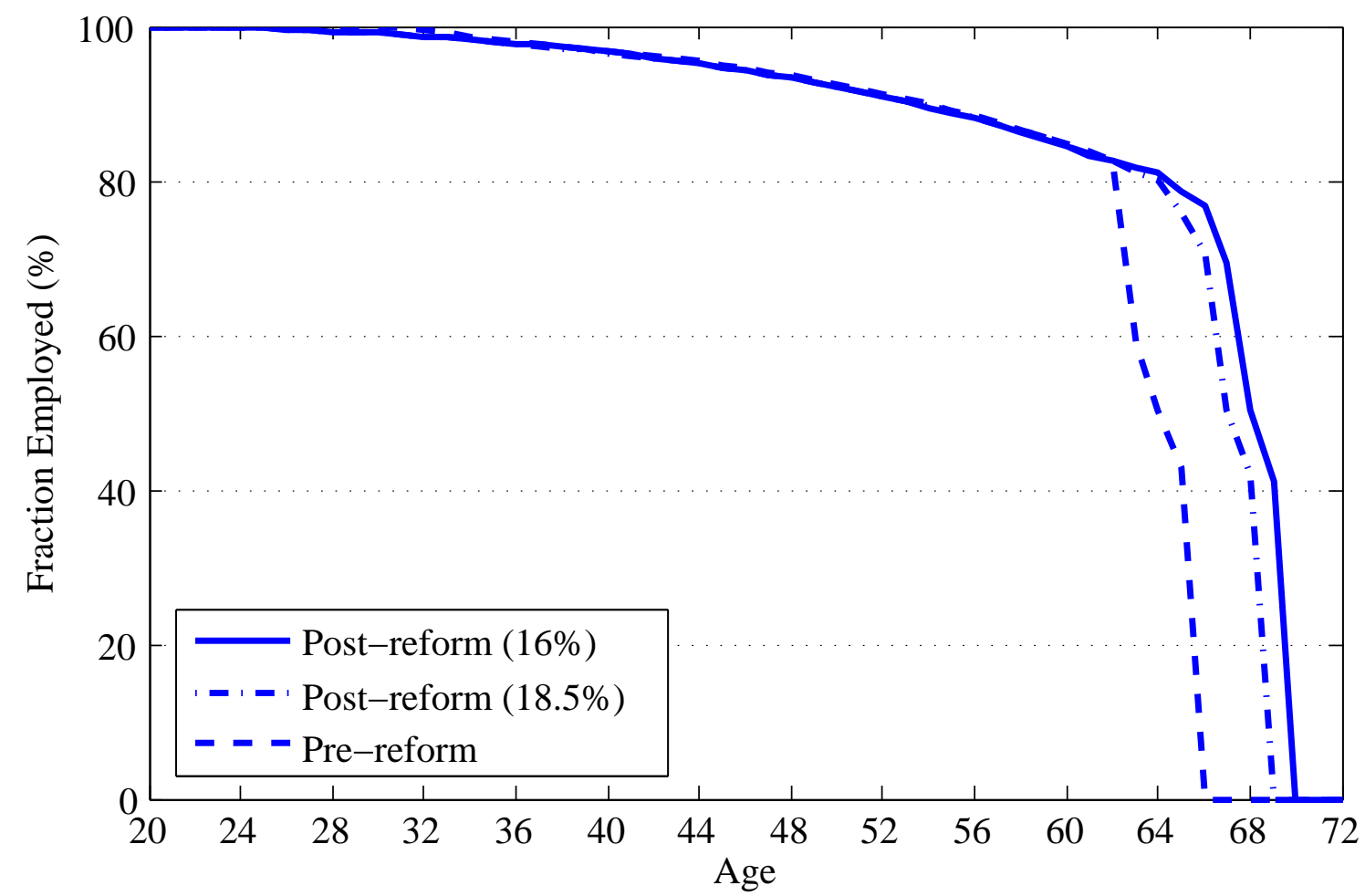

Figure 7: Fraction Employed by Age

In other words, the marginal utility of private consumption is unaffected by government consumption. We recalibrate the model to the old Swedish pension system with this assumption and study the labor supply implications of the pension reform. The setting with government consumption implies a slightly larger increase in the average retirement age following the pension reform than the setting with the lump-sum transfer, 2.6 years compared with 2.3 years.

To summarize, our results are robust to various model features. In fact, the sensitivity analysis presented in this section indicates that our baseline results are a conservative estimate of the labor supply effects of the recent Swedish pension reform.

\section{Conclusions}

We develop an overlapping generations model of life cycle labor supply and retirement to study the interactions between health, disability insurance and old-age pension benefits. 
In our framework, individuals care about their health, and can partially insure against negative health shocks. Agents choose when to stop working and, given eligibility criteria, if/when to claim disability insurance and pension benefits. The endogeneity of health and disability incidence are novel features of the framework in relation to the previous literature.

Having developed the model, we use it to study the labor supply implications of the recent Swedish pension reform. Our interest in Sweden naturally stems from the unique nature of the recent reform, but also from some of the inherent country characteristics. Much of the literature on disability insurance and pension claiming has centered on the United States. Many institutional features, such as healthcare, have potentially large implications for the labor supply outcomes of older workers. These institutions differ markedly between the United States and Sweden, or more generally most of Western Europe.

The Swedish reform entails a switch from a defined benefit to a defined contribution scheme. Under the old system, pension benefits were based only on income from the 15 highest years and only income up to a relatively low ceiling contributed to benefits. This had the potential of treating individuals with equivalent lifetime earnings very unequally. Moreover, under the old system disability insurance was extremely generous, treating the disabled individual as if he/she had earned the pre-disability income until age 65 . The pension reform seeks to address these issues.

We find that the new Swedish pension system creates large incentives for the continued employment of older individuals. In fact, the model predicts an increase in the average retirement age of 2.3 years, from 62.4 to 64.7 . We find that the incentives for working longer following the reform are two-fold. First, were one to retire at the same age in the new system as in the old system, the implied pension benefit would be lower. Second, unlike in the old system, in the new system the present value of lifetime pension benefits increases if one continues to work longer. Both effects are quantitatively important in accounting for the increase in the employment rates of older workers. Only a small share of the increase in aggregate labor supply comes from a decline in the fraction of people 
on disability insurance. In fact, the fraction of people to go on disability insurance during their lifetime only drops by roughly 1 percentage point, from $18.6 \%$ to $17.7 \%$. This is unsurprising, as it turns out that the present value of lifetime disability insurance and pension benefits for someone that went on disability insurance at, for example, age 50 declines only marginally following the reform. 


\section{References}

Berkovec, J., AND S. STERn (1991): “Job Exit Behavior of Older Men,” Econometrica, $59,189-210$.

Coile, C., And J. GRUBer (2007): "Future Social Security Entitlements and the Retirement Decision," The Review of Economics and Statistics, 89, 234-246.

Coile, C., And P. Levine (2007): "Labor Market Shocks and Retirement: Do Government Programs Matter?,' Journal of Public Economics, 91, 1902-1919.

FRENCH, E. (2005): “The Effects of Health, Wealth, and Wages on Labor Supply and Retirement Behavior," The Review of Economic Studies, 72, 395-427.

FRENCH, E., AND J. SONG (2009): “The Effect of Disability Insurance Receipt on Labor Supply," Working Paper 2009-05, Federal Reserve Bank of Chicago.

GRUber, J., AND D. Wise (2004): Social Security Programs and Retirement Around the World: Micro Estimation. University of Chicago Press.

(2009): Social Security Programs and Retirement Around the World: The Relationship to Youth Employment. University of Chicago Press.

Gustman, A., And T. Steinmeier (1986): “A Structural Retirement Model,” Econometrica, 54, 555-584.

JÖnSSON, L., M. PALME, AND I. SVEnsson (2011): “Disability Insurance, Population Health and Employment in Sweden," Discussion Paper 17054, National Bureau of Economic Research, Cambridge, MA.

LAUN, T. (2011): “Optimal Social Insurance with Endogenous Health,” Working paper.

Low, H., C. Meghir, And L. Pistaferri (2010): "Wage Risk and Employment Risk over the Life Cycle," American Economic Review, 100, 1432-1467. 
MCDANIEL, C. (2007): “Average Tax Rates on Consumption, Investment, Labor and Capital in the OECD 1950-2003," Working paper.

PALMER, E. (2003): “The New Swedish Pension System,” Working paper.

Pozzebon, S., And O. Mitchell (1989): "Married Women's Retirement Behavior," Journal of Population Economics, 2, 39-53.

Ragan, K. (2005): “Taxes, Transfers and Time Use: Fiscal Policy in a Household Production Model,” Working paper, University of Chicago.

Rogerson, R. (2007): “Taxation and Market Work: Is Scandinavia an Outlier?,” Economic Theory, 32, 59-85.

Rogerson, R., And J. Wallenius (2009): "Micro and Macro Elasticities in a Life Cycle Model with Taxes," Journal of Economic Theory, 144, 2277-2292.

(2011): “Fixed Costs, Retirement and the Elasticity of Labor Supply,” Working paper.

Rust, J., And C. Phelan (1997): "How Social Security and Medicare Affect Retirement Behavior in a World of Incomplete Markets," Econometrica, 65, 781-832.

Stock, J., AND D. Wise (1990): "Pensions, the Option Value of Work and Retirement," Econometrica, 58, 1151-1180.

SundÉn, A. (2006): “The Swedish Experience with Pension Reform,” Oxford Review of Economic Policy, 22, 133-148.

Sundén, D. (2002): “The Dynamics of Pension Reform,” Ph.D. thesis, Stockholm School of Economics.

Wallenius, J. (2009): "Social Security and Cross-Country Differences in Hours: A General Equilibrium Analysis,” Working paper. 